\title{
BMJ Open Informational value of percent body fat with body mass index for the risk of abnormal blood glucose: a nationally representative cross-sectional study
}

To cite: Jo A, Mainous III AG. Informational value of percent body fat with body mass index for the risk of abnormal blood glucose: a nationally representative crosssectional study. BMJ Open 2018;8:e019200. doi:10.1136/ bmjopen-2017-019200

- Prepublication history for this paper is available online. To view these files, please visit the journal online (http://dx.doi. org/10.1136/bmjopen-2017019200).

Received 17 August 2017 Revised 9 March 2018 Accepted 21 March 2018

Check for updates

${ }^{1}$ Department of Health Services Research, Management and Policy, College of Public Health and Health Professions, University of Florida, Gainesville, Florida, USA

${ }^{2}$ Department of Family Medicine and Community Health, College of Medicine, University of Florida, Gainesville, Florida, USA

Correspondence to Ara Jo; ara13j@ufl.edu

\section{ABSTRACT}

Objective To examine the value of percent body fat (\%BF) with body mass index (BMI) to assess the risk of abnormal blood glucose (ABG) among US adults who are normal weight or overweight. We hypothesised that normal-weight population with higher \%BF is more likely to have $A B G$.

Design A cross-sectional study.

Setting National Health and Nutrition Examination Survey, 1999-2006, conducted by the National Center for Health Statistics of the Centers for Disease Control and Prevention. Participants Participants were US adults aged 40 and older who have never been diagnosed with type 2 diabetes by a doctor (unweighted $n=6335$, weighted $n=65705$ 694). The study population was classified into four groups: (1) normal weight with normal \%BF, (2) normal weight with high \%BF, (3) overweight with normal \%BF and (4) overweight with high \%BF.

Main outcome measures $O R$ for $A B G$ including prediabetes and undiagnosed diabetes $(\mathrm{HbA} 1 \mathrm{C} \geq 5.7 \%$, $\geq 39 \mathrm{mmol} / \mathrm{mol}$ ).

Results $64 \%$ of population with normal BMI classification had a high \%BF. Prevalence of ABG in normal-weight group with high $\% \mathrm{BF}(13.5 \%)$ is significantly higher than the overweight group with low $\% \mathrm{BF}(10.5 \%, \mathrm{P}<0.001)$. In an unadjusted model, the $O R$ of $A B G$ was significantly greater in adults at normal BMI with high \%BF compared with individuals at normal weight with low \%BF. In an adjusted model controlling for age, sex, race/ethnicity, first-degree-relative diabetes, vigorous-intensity activities and muscle strengthening activities, risks of $A B G$ were greater in population with normal weight and high \%BF (OR 1.55, 95\% $\mathrm{Cl} 1.01$ to 2.38) and with overweight and low \%BF (OR 1.17, $95 \% \mathrm{Cl} 0.69$ to $1.98, \mathrm{P}<0.05$ ).

Conclusions Integrating $\mathrm{BMI}$ with $\% \mathrm{BF}$ can improve in classification to direct screening and prevention efforts to a group currently considered healthy and avoid penalties and stigmatisation of other groups that are classified as high risk of $A B G$.

\section{INTRODUCTION}

Diabetes has become a worldwide epidemic. It is one of the leading causes of morbidity and mortality in the USA, and its prevalence has been steadily increasing. ${ }^{2}$ The prevalence of diagnosed diabetes reached $12.3 \%$

\section{Strengths and limitations of this study}

The study used population-based nationally representative data allowing for generalisability.

- We used the most accurate body composition measurement, dual-energy X-ray absorptiometry (DXA) to assess direct impact of high body fat on abnormal blood glucose.

- Percent body fat integrating with body mass index improved classification of population who has high body fat associated with high risk of abnormal blood glucose.

- The data are relatively old while these are the most recent data including whole-body DXA measurement.

- There is no gold standard cut-off points in defining obesity according to percent body fat.

of US adults in 2011-2012. ${ }^{1}$ Furthermore, the total direct medical costs for diabetes was US $\$ 176$ billion in 2012 and healthcare expenditure for people with diabetes is two times higher than people without diabetes. ${ }^{3}$

In an effort to prevent diabetes and identify patients with undiagnosed diabetes for potential treatment, the United States Preventive Services Task Force (USPSTF) recommends screening of abnormal blood glucose (pre-diabetes or undiagnosed diabetes) for asymptomatic adults. ${ }^{45}$ The USPSTF recommends screening adults aged between 40 years old and 70 years old only if they are overweight or obese defined by body mass index (BMI) cut-offs. ${ }^{4}$ Recently, the Equal Employment Opportunity Commission (EEOC) proposed the rule that if employees who are overweight or obese fail to achieve a normal weight $\left(18.5-24.9 \mathrm{~kg} / \mathrm{m}^{2}\right)$ through wellness programmes, they penalise the employees who participate in wellness programmes up to $30 \%$ of the total costs of health insurance. ${ }^{6}$ Consequently, BMI levels have substantial implications for defining someone as low risk of abnormal blood glucose (ABG) or high risk of $\mathrm{ABG}$ 
BMI, which is widely adopted to assess obesity-related risk in clinical setting, however, may misclassify some segments of the general population who are at metabolic risk. While BMI is a simple equation based on height and weight, body weight includes body fat, muscle, bone and body water. ${ }^{7}$ Recent studies found that half of people who were obese according to percent body fat $(\% \mathrm{BF})$ but were classified as normal weight defined by BMI, and about $18 \%$ of adults with high $\% \mathrm{BF}$ who were classified as not being obese, showed a significant higher prevalence of metabolic syndrome. ${ }^{89}$ Recent data indicate that a significant proportion of people with a normal weight designated by BMI $\left(18.5-24.9 \mathrm{~kg} / \mathrm{m}^{2}\right)$ have pre-diabetes, undiagnosed diabetes and hypertension. ${ }^{10-12}$ In fact, $33 \%$ of adults 45 years old and older at a normal weight have pre-diabetes. Moreover, a normal weight obesity, which represents individuals who fall into normal range of BMI and who have high body fat mass, is associated with higher risk of metabolic syndrome, cardiometabolic dysregulation and cardiovascular mortality. ${ }^{13} 14$ On the other hand, professional football players who are typically classified as being obese due to high muscle mass actually showed better cardiovascular health compared with the general population. ${ }^{15}$

Because of the possible deleterious consequences due to BMI misclassification, \% BF may have some value as an addition to BMI to improve classification of individuals as low risk of $\mathrm{ABG}$ or high risk of ABG. ${ }^{16-18}$ However, the extent to which adding \% BF to BMI improves classification of risk is unclear. There has been little investigation to determine the incremental value of combining BMI and $\% \mathrm{BF}$ in a risk assessment for ABG. Therefore, the purpose of this study is to examine in a nationally representative sample the value of $\% \mathrm{BF}$ with $\mathrm{BMI}$ to assess the risk of abnormal glucose among adults who are normal weight or overweight and improve classification.

\section{METHODS}

We analysed the nationally representative, National Health and Nutrition Examination Survey (NHANES) for the years of 1999-2006. Although there are more recent NHANES data, these are the most recent data with a whole-body dual-energy X-ray absorptiometry (DXA) that measures \%BF. The NHANES is a national representative survey of non-institutionalised US population using a complex stratified multistage probability cluster sample design. To account for nationally representative population estimates, the National Center for Health Statistics applies a multilevel weighting system. The survey included a standardised medical examination including blood and urine analysis for examining biomarkers and a number of health-related interviews. The current study was approved as exempt by the Institutional Review Board at the University of Florida.

\section{Anthropometric assessment}

BMI was obtained from body weight divided by height squared $\left(\mathrm{kg} / \mathrm{m}^{2}\right)$. Weight and height were measured by a trained examiner in the mobile examination centre, and these were used to calculate BMI. ${ }^{19}$ BMI values were categorised into four groups (ie, underweight, normal weight, overweight and obesity) on the basis of guideline of the American Association of Clinical Endocrinologists (AACE) and the American College of Endocrinology (ACE). ${ }^{7} \% \mathrm{BF}$ was derived from one to three times weekly measured whole-body DXA scan (Hologic, Bedford, Massachusetts, USA) ${ }^{20} \mathrm{~A}$ sex-specific threshold of $\% \mathrm{BF}$ was adopted as $25 \%$ for men and $35 \%$ for women given by the AACE/ACE guideline (obesity in men $\geq 25 \%$ and women $\geq 35 \%$ ). ${ }^{7}$

\section{Participants}

The current study focused on adults aged over 40 years old or older who have never been told by a doctor or a health professional that they have diabetes (unweighted $\mathrm{n}=6335$ ). We focused on individuals 40 years old and older since 40 years old is the lower age cut-off for screening for ABG as suggested by the USPSTF. The study population was individuals with normal weight or overweight as defined by BMI. We limited the study to these individuals because they were the groups most likely to potentially be classified by the addition of \% BF to BMI.

Participants were limited to normal-weight and overweight population $\left(18.5-29.9 \mathrm{~kg} / \mathrm{m}^{2}\right)$ and classified as four groups based on combined BMI and \%BF. Respondents who were underweight and obese defined by BMI were excluded (missing $\mathrm{n}=5744)$. In normal BMI (18.5$24.9 \mathrm{~kg} / \mathrm{m}^{2}$ ), the first group who had normal BMI and low $\% \mathrm{BF}$ would be assessed to be at low risk. The second group may be classified as low risk of $A B G$ even though existing data suggest a substantial population have pre-diabetes (normal BMI but high \%BF). ${ }^{12}$ Among individuals classified as overweight by BMI $\left(25-29.9 \mathrm{~kg} / \mathrm{m}^{2}\right)$, the third group may be classified as high risk of $\mathrm{ABG}$, but they may be healthy due to the BMI limitation of not appropriately assessing extensive muscle mass (overweight and low \% BF). The fourth group would be at high risk based on having high fat (overweight and high \%BF). Pregnant women who were not allowed to test the DXA examination were excluded. Also, we excluded the obese population because of the known high risk.

\section{Outcomes}

The primary outcome is an abnormal glucose including pre-diabetes or undiagnosed diabetes, an HbA1c level of $5.7 \%$ or higher $(\geq 39 \mathrm{mmol} / \mathrm{mol})$. All subjects reported never having been told by a doctor or a health professional that they had pre-diabetes or diabetes. ${ }^{5}$ We excluded individuals with an $\mathrm{HbAlc}$ of $4.0 \%(\leq 20 \mathrm{mmol} / \mathrm{mol})$ that is associated with increased mortality without diabetes. ${ }^{21}$

\section{Covariates}

Age was classified into two groups with cut-offs of 40 years old and 71 years old. Race/ethnicity was categorised into four groups: (1) Non-Hispanic White, (2) Non-Hispanic Black, (3) Hispanics and (4) Other. Family history is a 
predictor of diabetes according to preliminary study. ${ }^{22}$ Thus, we selected family history of diabetes representing a first degree of relative ever being told by a health professional that they had diabetes.

We also assessed physical activity. Vigorous intensity activity helps to increase muscle mass and reduce body fat and it may result in overweight despite low \%BF. Also, physical activity represents a lifestyle intervention to control blood glucose. Vigorous activity was defined as reports of an activity that causes a slight to moderate increase in breathing or heart rate for at least $10 \mathrm{~min}$ over the past 30 days. Muscle strengthening activity refers to any physical activities designed to strengthen muscles including lifting weights, push-ups or sit-ups over the past 30 days.

\section{Statistical analysis}

To account for the stratified multistage probability sample design, we used SAS V.9.4 (Cary, North Carolina, USA) and SUDAAN software (RTI, Research Triangle Park, North Carolina, USA) for data analyses. Weighting and design variables applied to all analyses from univariate analyses, $\chi^{2}$ tests and logistic regression models. They allow us to calculate population estimates for non-institutionalised US population. We examined the bivariate relationship between combined $\mathrm{BMI} / \% \mathrm{BF}$ and abnormal glucose. Following by, both unadjusted and adjusted logistic regressions controlling for age, sex, race/ethnicity, family history of diabetes, vigorous activity and muscle strengthening activity were employed to assess the likelihood of having ABG.

\section{Patient and public involvement}

Patients and/or public were not involved in this study.

\section{RESULTS}

The total unweighted sample size was 6335 US adults representing 65705694 adults in the US population. No variable had more than $3 \%$ unweighted missing data and none of the demographics had any missing data. It is important to note that the population estimates are based on weighted sample. Table 1 shows that among normalweight population, approximately $64 \%$ of population of normal BMI classification had a high \%BF. Prevalence of

Table 1 Body mass index (BMI) classification among US adults aged over 40 or older who are normal weight and overweight stratified by $\mathrm{BMI}$ and percent body fat (\%BF) (unweighted $n=6335$ and weighted $n=65705$ 694)

\section{BMI $\left(\mathrm{kg} / \mathrm{m}^{2}\right)$}

\section{Normal (18.5-24.9 kg/ Overweight (25.0-} $\mathrm{m}^{2}$ ) $\left.29.9 \mathrm{~kg} / \mathrm{m}^{2}\right)$

\begin{tabular}{ccr}
\hline \%BF & & \\
Low & 36.3 & 9.0 \\
High & 63.7 & 91.0 \\
\hline
\end{tabular}

abnormal glucose by combined BMI and \% BF is shown in table 2. Prevalence of abnormal blood glucose in the normal weight group with high \%BF $(13.5 \%)$ is significantly higher than the overweight group with low $\% \mathrm{BF}$ $(10.5 \%)(\mathrm{P}<0.001)$. About $78 \%$ of the study population was adults aged between 40 years old and 70 years old and non-Hispanic white. In sex, most men showed low $\% \mathrm{BF}$ whereas more than $70 \%$ of women have a high level of body fat within normal-weight population. Regardless of BMI, more than $40 \%$ of the study population with low $\% \mathrm{BF}$ performed vigorous-intensity activity as well as muscle strengthening activity compared with population with high \% BF $(\mathrm{P}<0.001)$.

In an unadjusted logistic regression, the $\mathrm{OR}$ of abnormal glucose was significantly greater in adults at normal weight with high $\% \mathrm{BF}$ compared with individuals at normal weight with low $\% \mathrm{BF}$ as the reference group (table 3). Conversely, ABG risk was not significantly more likely in overweight adults with low $\% \mathrm{BF}$ when compared with the normal-weight/low \%BF group. In an adjusted model controlling for age, sex, race/ethnicity, first-degree-relative diabetes, vigorous-intensity activities and muscle strengthening activities, the adjusted model results were similar to the unadjusted results. Risks of ABG were greater in population with normal weight and high $\% \mathrm{BF}$ as well as the overweight with high \% BF (table 3).

In sensitivity analyses, area under the curve of combined form of BMI and \% BF was larger than areas of BMI only or $\% \mathrm{BF}$ only (figure 1$)$. These areas were significantly different $(\mathrm{P}<0.001)$.

\section{DISCUSSION}

The use of BMI only may misclassify segments of the adult population in terms of risk of abnormal glucose. Our key findings showed that individuals with normal weight who have high \%BF have significantly higher risk of abnormal glucose compared with individuals with normal weight and low \%BF. Conversely, of individuals with overweight, low $\% \mathrm{BF}$ is not significantly associated with the risk of abnormal glucose. The results suggest that $\% \mathrm{BF}$ combined with BMI may help to improve risk stratification for ABG in these intermediate groups.

Since body weight comprises fat and also a variety of body compositions such as muscle, organs and body water, it may not estimate the actual amount of body fat. Professional football players who are typically classified as obese due to high muscle mass showed better cardiovascular health compared with the general population. ${ }^{15}$ In addition, among military population, whereas an average of BMI was overweight, almost half of them had never had any form of sickness absence. ${ }^{23}$ Furthermore, since according to our preliminary study $33 \%$ of normal-weight population has pre-diabetes, $\% \mathrm{BF}$ may identify this normal-weight population at risk of development of ABG. ${ }^{11}$ These evidences indicate that $\% \mathrm{BF}$ may be a key factor in improving to estimate risk of chronic disease. 
Table 2 Baseline characteristics of adults aged over 40 or older who are normal weight and overweight (unweighted $\mathrm{n}=6335$ and weighted $\mathrm{n}=65705$ 694)

\begin{tabular}{|c|c|c|c|c|c|}
\hline \multirow{2}{*}{$\begin{array}{l}\text { Body mass index } \\
\% \text { Body fat }\end{array}$} & \multicolumn{2}{|l|}{ Normal } & \multicolumn{2}{|l|}{ Overweight } & \multirow[b]{2}{*}{$P$ values } \\
\hline & Low & High & Low & High & \\
\hline Unweighted sample size & 908 & 1679 & 327 & 3421 & \\
\hline Weighted sample size & 10259138 & 18020486 & 3382474 & 34043596 & \\
\hline Prevalence of abnormal blood glucose & 8.6 & 13.5 & 10.5 & 20.0 & $<0.001$ \\
\hline \multicolumn{6}{|l|}{ Age } \\
\hline 40 to 70 & 92.3 & 81.1 & 96.0 & 85.2 & $<0.001$ \\
\hline 71 or older & 7.7 & 18.9 & 4.0 & 14.8 & \\
\hline \multicolumn{6}{|l|}{ Sex } \\
\hline Male & 61.1 & 28.8 & 96.2 & 53.4 & $<0.001$ \\
\hline Female & 38.9 & 71.2 & 3.8 & 46.6 & \\
\hline \multicolumn{6}{|l|}{ Race } \\
\hline Non-Hispanic white & 77.5 & 80.4 & 70.4 & 77.0 & $<0.001$ \\
\hline Non-Hispanic black & 11.7 & 4.8 & 17.0 & 8.0 & \\
\hline Hispanics & 6.5 & 7.1 & 10.0 & 10.9 & \\
\hline Others & 4.3 & 7.7 & 2.6 & 4.2 & \\
\hline \multicolumn{6}{|l|}{ First-degree-relative diabetes } \\
\hline Yes & 35.9 & 45.5 & 43.6 & 46.9 & $<0.001$ \\
\hline No & 64.2 & 54.5 & 56.4 & 53.1 & \\
\hline \multicolumn{6}{|l|}{ Vigorous activity } \\
\hline Yes & 41.7 & 28.1 & 45.9 & 30.4 & $<0.001$ \\
\hline No & 58.3 & 71.9 & 54.1 & 69.6 & \\
\hline \multicolumn{6}{|l|}{ Muscle-strengthening activities } \\
\hline Yes & 40.5 & 25.1 & 38.1 & 23.4 & $<0.001$ \\
\hline No & 59.5 & 74.9 & 61.9 & 76.7 & \\
\hline
\end{tabular}

Our key findings may suggest refinement of current clinical guidelines with additional body composition assessments. The USPSTF and the American Diabetes Association have BMI as a key component of recommendations for diabetes prevention. ${ }^{45}$ There may be missed opportunities for screening, particularly for pre-diabetes. Regardless of BMI, people with high \% BF were older, female and non-Hispanic white. While the proportion of family history patients positive for diabetes was similar across four groups, physical activity was different among groups. It is particularly important, as shown in our findings, that we appropriately classify the overweight population with low $\% \mathrm{BF}$. This population has been neglected as being classified as a healthy population. Our finding showed that these individuals are significantly more likely to perform high-intensity physical activities compared with the normal-weight population who had low \% BF, and this behaviour may result in overweight. For instance, professional athletes or civil forces with higher muscle mass who are typically classified as obese measured by BMI may fail to meet normal BMI criteria in recruitment screening. ${ }^{24}$ In addition,

Table 3 OR $(95 \% \mathrm{Cl})$ for the abnormal glucose for adults with normal weight and overweight in unadjusted and adjusted logistic regression models controlling for age, sex, race/ethnicity, first-degree-relative diabetes, vigorous activities and musclestrengthening activity

\begin{tabular}{llll}
\hline BMI & \%BF & Unadjusted OR & Adjusted OR \\
\hline Normal $\left(18.5-24.9 \mathrm{~kg} / \mathrm{m}^{2}\right)$ & Low & 1.00 & 1.00 \\
& High & $1.66(1.13 \text { to } 2.43)^{\star}$ & $1.55(1.01 \text { to } 2.38)^{\star}$ \\
Overweight $\left(25-29.9 \mathrm{~kg} / \mathrm{m}^{2}\right)$ & Low & $1.25(0.75$ to 2.07$)$ & $1.17(0.69$ to 1.98$)$ \\
& High & $2.64(1.86 \text { to } 3.76)^{\star}$ & $2.45(1.61 \text { to } 3.71)^{\star}$
\end{tabular}

*Statistically significant at 0.05 .

$\mathrm{BMI}$, body mass index; \%BF, percent body fat. 
A

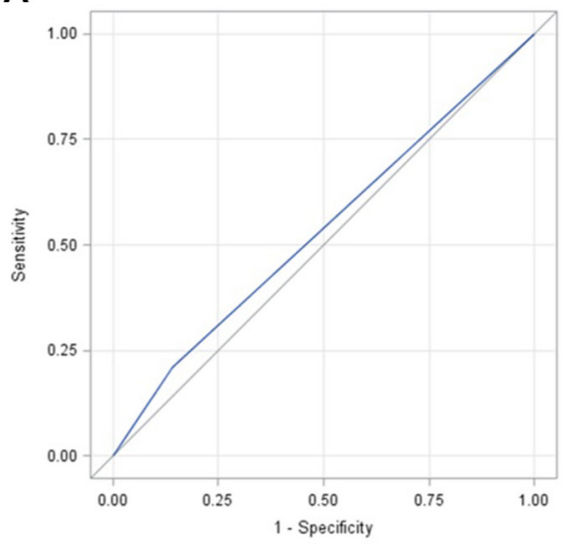

C

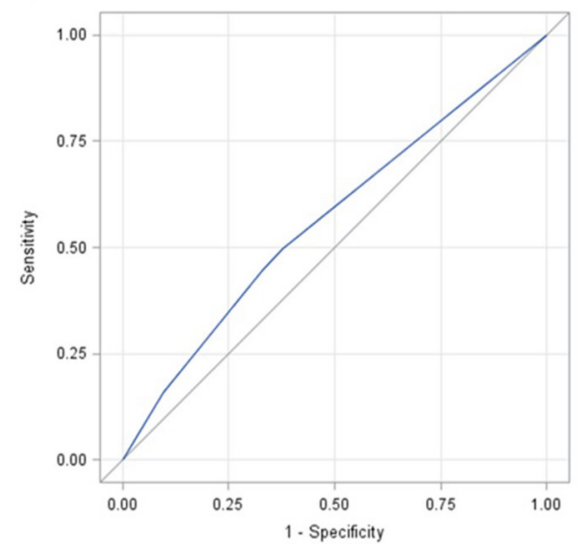

B

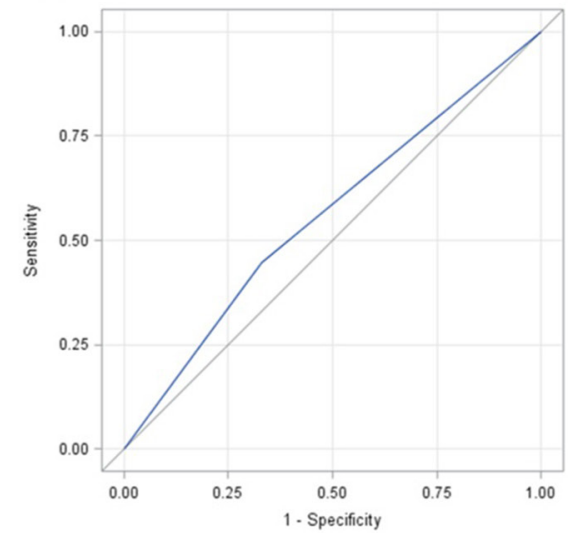


of DXA scan for the purpose of screening of chronic diseases. Bioelectrical impedance analysis, which assesses $\% \mathrm{BF}$, may be a cost-effective alternative for the purpose of ABG screening in primary care setting, while the current study used the data measured by DXA scan.

\section{CONCLUSION}

BMI, which is typically used to define normal weight or overweight in a clinical setting, may misclassify populations in relation to $\mathrm{ABG}$. Integrating $\mathrm{BMI}$ with \% BF can help in classification to direct screening and prevention efforts to a group currently considered low risk of ABG and avoid penalties and stigmatisation of other groups that are classified as high risk of ABG.

Contributors AJ led the entire research as the first author from writing the manuscript, analysing the data and interpretation. AGM supervised the entire process of the research as a research mentor and contributed to writing the manuscript.

Funding This research received no specific grant from any funding agency in the public, commercial or not-for-profit sectors.

Competing interests None declared.

Patient consent Not required.

Ethics approval This study was approved as exempt by the Institutional Review Board at the University of Florida.

Provenance and peer review Not commissioned; externally peer reviewed.

Data sharing statement Data are available through the National Health and Nutrition Examination Survey access (https://www.cdc.gov/nchs/nhanes/index.htm).

Open Access This is an Open Access article distributed in accordance with the Creative Commons Attribution Non Commercial (CC BY-NC 4.0) license, which permits others to distribute, remix, adapt, build upon this work non-commercially, and license their derivative works on different terms, provided the original work is properly cited and the use is non-commercial. See: http://creativecommons.org/ licenses/by-nc/4.0/

(c) Article author(s) (or their employer(s) unless otherwise stated in the text of the article) 2018. All rights reserved. No commercial use is permitted unless otherwise expressly granted.

\section{REFERENCES}

1. Menke A, Casagrande S, Geiss L, et al. Prevalence of and trends in diabetes among adults in the United States, 1988-2012. JAMA 2015;314:1021-9.

2. Ma J, Ward EM, Siegel RL, et al. Temporal trends in mortality in the United States, 1969-2013. JAMA 2015;314:1731-9.

3. American Diabetes Association. Economic costs of diabetes in the U.S. in 2012. Diabetes Care 2013;36:1033.

4. U.S. Preventive Services Task Force. U.S. Final Recommendation Statement: Healthful Diet and Physical Activity: Counseling Adults with High Risk for CVD. Rockville, MD: US Preventive Services Task Force, 2014.
5. ADA. Standards of medical care in diabetes-2016. Diabetes Care 2016;39(Suppl 1):S1-106.

6. EEOC. Questions and answers about EEOC's notice of proposed rulemaking on employer wellness programs. Washington, DC: US Equal Employment Opportunity Commission.

7. Dickey RA, Bartuska DG, Bray GW, et al. AACE/ACE Position statement on the prevention, diagnosis, and treatment of obesity (1998 revision). Endocr Pract 1998;4:297-350.

8. Okorodudu DO, Jumean MF, Montori VM, et al. Diagnostic performance of body mass index to identify obesity as defined by body adiposity: a systematic review and meta-analysis. Int $J$ Obes 2010;34:791-9.

9. Peterson MD, Al Snih S, Stoddard J, et al. Obesity misclassification and the metabolic syndrome in adults with functional mobility impairments: Nutrition Examination Survey 2003-2006. Prev Med 2014;60:71-6.

10. Mainous AG, Tanner RJ, Anton SD, et al. Grip strength as a marker of hypertension and diabetes in healthy weight adults. Am J Prev Med 2015;49:850-8.

11. Mainous AG, Tanner RJ, Anton SD, et al. Physical activity and abnormal blood glucose among healthy weight adults. Am J Prev Med 2017;53:42-7.

12. Mainous AG, Tanner RJ, Jo A, et al. Prevalence of prediabetes and abdominal obesity among healthy-weight adults: 18-year trend. Ann Fam Med 2016;14:304-10.

13. Marques-Vidal P, Pécoud A, Hayoz D, et al. Prevalence of normal weight obesity in Switzerland: effect of various definitions. Eur J Nutr 2008;47:251-7.

14. Oliveros E, Somers VK, Sochor O, et al. The concept of normal weight obesity. Prog Cardiovasc Dis 2014;56:426-33.

15. Tucker AM, Vogel RA, Lincoln AE, et al. Prevalence of cardiovascular disease risk factors among National Football League players. JAMA 2009;301:2111-9.

16. Romero-Corral A, Somers VK, Sierra-Johnson J, et al. Normal weight obesity: a risk factor for cardiometabolic dysregulation and cardiovascular mortality. Eur Heart J 2010;31:ehp487.

17. Shea JL, King MT, Yi Y, et al. Body fat percentage is associated with cardiometabolic dysregulation in BMI-defined normal weight subjects. Nutr Metab Cardiovasc Dis 2012;22:741-7.

18. Gallagher D, Heymsfield SB, Heo M, et al. Healthy percentage body fat ranges: an approach for developing guidelines based on body mass index. Am J Clin Nutr 2000;72:694-701.

19. CDC. NHANES: anthropometric procedures manual. Atlanta, GA: CDC, 2007

20. NHANES. Documentation, codebook, and frequencies: dual-energy $X$-ray absorptiometry. Atlanta, GA: NHANES, 2008.

21. Carson AP, Fox CS, McGuire DK, et al. Low hemoglobin A1c and risk of all-cause mortality among US adults without diabetes. Circ Cardiovasc Qual Outcomes 2010;3:661-7.

22. von Eckardstein A, Schulte H, Assmann G. Risk for diabetes mellitus in middle-aged Caucasian male participants of the PROCAM study: implications for the definition of impaired fasting glucose by the American Diabetes Association. Prospective Cardiovascular Münster. $J$ Clin Endocrinol Metab 2000;85:3101-8.

23. Kyröläinen $\mathrm{H}$, Häkkinen $\mathrm{K}$, Kautiainen $\mathrm{H}$, et al. Physical fitness, $\mathrm{BMI}$ and sickness absence in male military personnel. Occup Med 2008;58:251-6.

24. Prentice AM, Jebb SA. Beyond body mass index. Obes Rev 2001;2:141-7.

25. Cappuccio FP, D'Elia L, Strazzullo P, et al. Quantity and quality of sleep and incidence of type 2 diabetes: a systematic review and meta-analysis. Diabetes Care 2010;33:414-20.

26. Cappuccio FP, Taggart FM, Kandala NB, et al. Meta-analysis of short sleep duration and obesity in children and adults. Sleep 2008;31:619-26. 
Correction: Informational value of percent body fat with

body mass index for the risk of abnormal blood glucose: a nationally representative cross-sectional study

Jo A, Mainous III AG. Informational value of percent body fat with body mass index for the risk of abnormal blood glucose: a nationally representative cross-sectional study. BMJ Open 2018;8:e019200. doi: 10.1136/bmjopen-2017-019200

The suffix 'III' in the surname of author 'Arch G Mainous III' should be written as '3rd' to match his other publications.

Open Access This is an Open Access article distributed in accordance with the Creative Commons Attribution Non Commercial (CC BY-NC 4.0) license, which permits others to distribute, remix, adapt, build upon this work non-commercially, and license their derivative works on different terms, provided the original work is properly cited and the use is non-commercial. See: http://creativecommons.org/licenses/by-nc/4.0/

(C) Article author(s) (or their employer(s) unless otherwise stated in the text of the article) 2018. All rights reserved. No commercial use is permitted unless otherwise expressly granted.

BMJ Open 2018;8:e019200corr1. doi:10.1136/bmjopen-2017-019200corr1

A) Check for updates 